\title{
A educação de jovens e adultos no Brasil: entre trajetórias descontínuas e a expectativa do direito
} Youth and adult education in Brazil: between paths discontinuous and the expectation of
the right

iD Jupter Martins de Abreu Júnior Doutor em Educação pela Universidade do Estado do Rio de Janeiro (UERJ). Docente do Instituto Federal do Rio de Janeiro (IFRJ), Duque de Caxias - RJ, Brasil. jupter.junior@ifrj.edu.br

Helen Wanderley do Prado Doutora em Educação pela Universidade Federal do Estado do Rio de Janeiro (UNIRIO). Técnica em Assuntos Educacionais (TAE) do Instituto Federal do Rio de Janeiro (IFRJ). Duque de Caxias - RJ, Brasil. helen.prado@ifrj.edu.br

Resumo: O presente artigo visa, a partir de revisão bibliográfica e análise documental, discutir os aspectos históricos e teóricos do direito à educação, relacionando-os com a Educação de Jovens e Adultos (EJA) no Brasil. Os referenciais utilizados abarcam autores que apresentam uma visão ampla do direito, como Marshall e Bobbio; outros que se dedicam às discussões do direito à educação, como Cury; além de pesquisadores que estudam especificamente a EJA, como Paiva e Machado. $\mathrm{O}$ artigo pretende contribuir no sentido de ampliar a visibilidade do movimento do direito à educação, ratificando que esta ação sempre enfatizou a luta pela dignidade humana e o princípio da igualdade. Constatou-se que é necessário a implementação de políticas públicas que tenham como foco diminuir as desigualdades historicamente acumuladas, garantindo o acesso, a permanência e o êxito na aprendizagem dos sujeitos da EJA.

Palavras-chave: Direito à educação. Direito social. EJA.

Abstract: This article aims, based on bibliographical review and documentary analysis, to discuss the historical and theoretical aspects of the right to education, relating them to the Youth and Adult Education (YAE) in Brazil. The references used include authors who present a broad view of the right, such as Marshall and Bobbio; others who are dedicated to the discussions of the right to education, such as Cury; in addition to researchers who specifically study YAE, such as Paiva and Machado. The article intends to contribute towards broadening the visibility of the right to education movement, ratifying that this action has always emphasized the struggle for human dignity and the principle of equality. It has been found that it is necessary to implement public policies that focus on reducing the historically accumulated inequalities, guaranteeing the access, permanence, and success in learning of YAE subjects.

Keywords: Right to education. Social right. Youth and adult education. 
ABREU JÚNIOR, Jupter Martins de; PRADO, Helen Wanderley do. A educação de jovens e adultos no Brasil: entre trajetórias descontínuas e a expectativa do direito

\section{Introdução}

O acesso ao que hoje denominamos no Brasil como a modalidade Educação de Jovens e Adultos (EJA) se estabeleceu de forma gradativa como um direito constitucionalmente garantido. Entretanto, a trajetória dessa modalidade ao longo da história da educação brasileira reflete uma série de descontinuidades, momentos de instabilidade e de negação de direitos. Conforme destaca Bobbio (2004, p. 22) “os direitos naturais são direitos históricos, nascem na era moderna, juntamente com a concepção individualista da sociedade, e tornam-se um dos principais indicadores do progresso histórico". Baseado nessas considerações, observa-se que os direitos do homem nascem gradualmente e são consequências de circunstâncias históricas e das disputas sociais.

Inserida nessa realidade, nas últimas décadas a educação tornou-se um dos principais focos de atenção da sociedade, sendo considerada um dos elementos fundamentais da cidadania. Ademais, como tal, tem impacto e relevância na conjuntura das políticas que têm por meta o incremento da participação da sociedade nos espaços sociais e políticos, assim como na inserção e reinserção no mundo do trabalho.

Deste modo, mediante os argumentos expostos, o presente artigo pretende, a partir de revisão bibliográfica e análise documental, discutir os aspectos históricos e teóricos do direito à educação, relacionando-os com a educação de jovens e adultos no Brasil. O referencial teórico utilizado abarca autores que apresentam uma visão ampla do direito, como Marshall (2002) e Bobbio (2004); outros que se dedicam às discussões sobre direito à educação, como Cury (2008a, 2008b, 2013); além de pesquisadores que estudam especificamente a EJA, como Paiva (2009) e Machado (2009).

\section{Direito e Educação: aspectos históricos}

Dentre os autores que se dedicaram a compreender a trajetória dos direitos, destaca-se o trabalho de Thomas Marshall (2002), tanto no sentido de qualificá-los quanto para apresentar suas transformações ao longo do tempo. Possuindo, dessa forma, uma produção que pode ampliar o entendimento das relações entre direito e cidadania.

As considerações de Marshall (2002) sobre o direito à educação escolar ressaltam semelhanças existentes na luta estabelecida por uma legislação protetora dos trabalhadores da então recente indústria inglesa dos séculos XVIII e XIX. As argumentações sugerem que, no caso do direito à educação ou mesmo nas leis de proteção aos trabalhadores, o século XX foi o período em que se lançaram as bases para os direitos sociais como parte integrante da cidadania. 
ABREU JÚNIOR, Jupter Martins de; PRADO, Helen Wanderley do. A educação de jovens e adultos no Brasil: entre trajetórias descontínuas e a expectativa do direito

Com esse legado do século XX, o direito ao trabalho e o direito à educação do trabalhador se apresentaram como ferramentas para a efetivação da cidadania no século XXI. Assim, consideramos que as possíveis mudanças que vêm ocorrendo na sociedade são processos dinâmicos que romperam com paradigmas já instituídos, exigindo reflexões e (re)contextualizações diversas.

Na intenção de ampliar a compreensão desses processos, os esclarecimentos de Marshall (2002) destacam que a educação é um pré-requisito necessário tanto para a conquista da liberdade civil quanto para o exercício de outros direitos. Segundo o autor, a ação do Estado em intervir na sociedade por meio da instrução escolar alteraria o contrato social estabelecido até o século XIX. Contudo, essa ação não estaria conflitando com os direitos civis já estabelecidos na Inglaterra desde o século XVIII, pois a relevância da educação para o desenvolvimento econômico do país viria se consolidar gradativamente até atingir o status de indispensável.

Em concordância com as premissas de Cury (2013) e Bobbio (2004), é possível afirmar que a relação entre direito à educação e democracia tem a legislação como um de seus principais suportes, e o Estado como agente executor e provedor. Enfatizamos ainda que o Estado pode se ausentar do cumprimento de seus deveres, ocasionando embates em que, para além dos direitos, visualiza-se a luta pela reafirmação da democracia.

Ao realizar esse debate, Marshall (2002) destaca que a educação escolar primária, inicialmente, era pensada como um serviço extra, e que deveria ser ofertada de maneira única aos indivíduos, nos moldes de aulas particulares. Em momento posterior, o autor ressalta que "o desenvolvimento da educação primária pública durante o século XIX constituiu um passo decisivo em prol do restabelecimento dos direitos sociais da cidadania no século XX” (ibidem, p. 74).

No entanto, Cury (2013) indica que os governos de alguns países europeus perceberam que, no tocante à educação, para contar com as classes populares no sentido da solução de problemas não era mais possível nem deixar de satisfazer algumas de suas exigências e nem ser um privilégio. O que, a rigor, era direito de todos e não só de uma minoria.

Nesse sentido, ao discutir questões relacionadas à construção de direitos, tendo como foco os valores da cidadania social e política, Cury (2013) destaca que o Estado, como "organismo" que parte da premissa racional, deveria seguir a razão e seus pareceres. Cabendo-lhe assegurar meios para que os cidadãos tivessem condições de agir segundo o seu próprio arbítrio. Tendo, para tanto, que seguir "as luzes da razão", que seriam consequência natural do acesso à educação.

Contudo, é necessário considerar que a inscrição de um direito na legislação de um país ou região não acontece de forma instantânea, mas se trata de uma ação histórica e social que se tem 
ABREU JÚNIOR, Jupter Martins de; PRADO, Helen Wanderley do. A educação de jovens e adultos no Brasil: entre trajetórias descontínuas e a expectativa do direito

constituído de maneira mais efetiva a partir da Era Moderna. Em concordância com essa premissa, Bobbio (2004, p. 05) menciona que:

[...] os direitos do homem, por mais fundamentais que sejam, são direitos históricos, ou seja, nascidos em certas circunstâncias, caracterizadas por lutas em defesa de novas liberdades contra velhos poderes, e nascidos de modo gradual, não todos de uma vez e nem de uma vez por todas.

Ressalta-se o caráter histórico da afirmação dos direitos humanos. De maneira que o próprio Bobbio (2004) também destaca a importância das liberdades conquistadas a partir da perspectiva de formação do Estado Moderno, que passou a ter como foco a relação Estado/cidadão.

\section{A EJA no Brasil: entre expectativas e trajetórias descontínuas}

O Brasil é um país oriundo de uma realidade escravocrata e de forte tradição elitista. Em decorrência dessa trajetória, somente na Constituição Federal de 1934 a educação foi declarada direito de todos. Impulsionada por essa orientação, a Carta Magna de 1934, de acordo com Cury (2008b), representou um incremento na área educacional. Já que conquistas, como a liberdade de cátedra e a regulação de percentuais mínimos a serem aplicados na educação, eram indicativos de reconhecimento do valor da educação para o desenvolvimento sociocultural do país.

Apesar dos avanços, também se observa que na Constituição de 1934 havia limitações com relação à matrícula, vinculada à infraestrutura física dos estabelecimentos, aspecto que resultaria em processos de seleção. A partir desses encaminhamentos, para aqueles que concluíam o ensino primário e tinham a intenção de prosseguir os estudos, era necessário serem aprovados nos chamados "exames de admissão". Dessa forma, identificamos que nesse período a oferta de vagas dependeria da estrutura, proposta pedagógica e recursos humanos das unidades de ensino. Além de que a gratuidade poderia não existir, conforme as alterações da legislação em nível estadual.

Com a instituição do "Estado Novo" de Getúlio Vargas, uma nova constituição foi outorgada em 1937, que teve como consequência algumas transformações no direcionamento que vinha ocorrendo na educação brasileira. Deste modo, se estabeleceu um aumento de privilégios concedidos ao ensino privado, mostrando a intenção do governo getulista em se eximir dos deveres sobre a educação. A partir desses encaminhamentos, observamos que a educação havia se tornado uma responsabilidade quase exclusiva das famílias e da sociedade civil, diminuindo os avanços conquistados em 1934 com relação a esse direito.

Em 1938 houve a criação do Instituto Nacional de Estudos Pedagógicos (INEP) e suas pesquisas levaram à necessidade de conceber um Fundo Nacional do Ensino Primário (FNEP), 
ABREU JÚNIOR, Jupter Martins de; PRADO, Helen Wanderley do. A educação de jovens e adultos no Brasil: entre trajetórias descontínuas e a expectativa do direito

proposto em 1942. Com os recursos desse fundo deveriam ser realizados programas, dentre os quais estava inclusa uma proposta denominada ensino primário supletivo. Esta teria como meta a ampliação da escolarização básica para os diversos setores da sociedade, estando inseridos nestes grupos adolescentes e adultos subescolarizados e analfabetos, que seriam futuramente identificados como público da EJA.

O FNEP foi regulamentado de forma que $25 \%$ dos recursos destinados ao Fundo deveriam ser aplicados em programas destinados a esse grupo. Entretanto, ainda que estas ações indicassem o início de um movimento para a existência de políticas com foco no público da EJA, também se constatava o caráter compensatório da proposta, viés que se afastava da perspectiva do direito à educação.

No intento de avançar nessa discussão, percebemos algumas contradições existentes em outras bases legais do período. Dentre as quais destacamos a Lei Orgânica do Ensino Normal, que, de acordo com Romanelli (2014), foi regulamentada pelo Decreto $\mathrm{n}^{\circ}$ 8.530, de 1946. Essa normativa impedia a admissão de candidatos maiores de vinte e cinco anos no curso de formação de professores.

Considerando a realidade brasileira da década de 1940, na qual a maioria do pessoal empregado no magistério primário não possuía formação para a função, pertencendo a uma faixa etária que excedia esse limite da idade, percebe-se que essa determinação impedia a qualificação de quem já exercia o magistério sem possuir a formação oficial. Deste modo, é possível observar mais um caso no qual o Estado, por meio de dispositivos legais, nega o direito do acesso à educação e à formação profissional aos cidadãos.

Apesar de existirem caminhos controversos, com a Constituição Federal de 1946, promulgada após o fim do Estado Novo, buscou-se recompor o modelo educacional idealizado pela Constituição de 1934, o qual fora desestruturado pela Carta outorgada em 1937, durante o regime getulista. De acordo com Romanelli (2014), na Constituição de 1946 a educação voltava a ser direito de todos, com a obrigatoriedade e gratuidade do ensino primário. Além do retorno da aplicação compulsória de percentuais mínimos da renda dos impostos na educação por parte de estados, municípios, Distrito Federal e União. A Carta de 1946 também determinava a criação de sistemas estaduais de ensino, tendo o sistema federal uma atuação supletiva, ou seja, atuaria somente para suprir eventuais deficiências locais.

Alguns autores, como Paiva (2009) e Romanelli (2014), ressaltam a importância das ações desenvolvidas a partir da década de 1940, destacando a Campanha Nacional de Educação de Adolescentes e Adultos (CEAA), capitaneada por Lourenço Filho. A CEAA começou em 1947, 
ABREU JÚNIOR, Jupter Martins de; PRADO, Helen Wanderley do. A educação de jovens e adultos no Brasil: entre trajetórias descontínuas e a expectativa do direito

estendendo-se até fins da década de 1950, representando uma política pública que manifestava o entendimento da educação de adultos como peça fundamental na elevação da escolaridade da população.

Nesse sentido, ressaltamos que as ações de Lourenço Filho à frente da CEAA ampliavam os efeitos positivos que a educação de adultos tinha sobre a escolarização das crianças. Uma vez que ambas deveriam fazer parte de um mesmo projeto de ascensão cultural e social dos cidadãos, compondo um movimento que concretizaria de maneira efetiva o direito à educação. Dessa forma, por meio de ações como a CEAA, observamos um aumento nas atribuições e responsabilização do Estado brasileiro com relação ao público da EJA. Assim como um momento em que setores da sociedade com menor poder econômico intensificaram a cobrança pelo direito à educação.

Em decorrência do trabalho realizado nas décadas de 1940 e 1950, houve queda nos índices de analfabetismo no país. De acordo com Ferraro e Kreidlow (2004), se em 1920 os dados disponíveis indicavam que $71,2 \%$ da população brasileira acima de cinco anos de idade era analfabeta, em 1960 esses índices diminuíram para 46,7\%. Esses resultados, embora positivos, mostravam que a efetivação do direito à educação no Brasil ainda se encontrava longe do nível dos países do então chamado "primeiro mundo", ou mesmo de alguns vizinhos da América Latina.

Ao observar esses indicadores, constata-se que havia um longo caminho para se trilhar, e que demandas emanavam dos diversos setores da sociedade de forma cada vez mais intensa. Como agravante, a realidade de descontinuidade das políticas públicas educacionais colaborava para que os menos favorecidos ficassem num plano secundário, impedindo a ampliação do direito à educação para este público.

Após a promulgação da Constituição de 1946, foram necessários quinze anos de discussão entre os grupos que defendiam a educação pública e o ensino privado para que fosse possível a aprovação da primeira Lei de Diretrizes e Bases da Educação Nacional (LDBEN), nº 4.024/1961. O texto do documento caracterizou-se por evidenciar, conforme destacam Shiroma, Moraes e Evangelista (2004, p. 25), “a vitória das forças conservadoras e privatistas, além dos prejuízos quanto à distribuição de recursos públicos e a ampliação das oportunidades de acesso à educação". Isso porque a Lei deixava possibilidades para que o ensino primário obrigatório não fosse cumprido, pois trazia como atenuantes para não frequentar a escola os seguintes casos:
a) comprovado estado de pobreza do pai ou responsável;
b) insuficiência de escolas;
c) matrícula encerrada;
d) doença ou anomalia grave da criança (BRASIL, 1961). 
ABREU JÚNIOR, Jupter Martins de; PRADO, Helen Wanderley do. A educação de jovens e adultos no Brasil: entre trajetórias descontínuas e a expectativa do direito

Ressaltamos que a Lei n⿳ 4.024/1961, ao explicitar as isenções da obrigatoriedade, apresenta de forma direta quem não precisaria ter acesso à educação e usufruir deste direito. Sobre esse fato, observamos em Cury (2008b, p. 214) um comentário sobre esse trecho da LDBEN, no qual o autor destaca que:

Raramente a face da desigualdade social, fruto de relações econômicas, sociais, políticas e culturais, foi tão clara: o indivíduo em "estado de pobreza" está privado das virtudes de um direito proclamado como essencial para a vida social.

O posicionamento de Cury caracteriza a contradição de um momento no qual, embora a Carta de 1946, então vigente, regulamentasse que a educação era um direito de todos e que devia se inspirar nos princípios de liberdade e nos ideais de solidariedade humana, o próprio Estado, por meio de mecanismos legais, iria contribuir para a desigualdade social e para o descumprimento do direito de acesso à educação.

\section{O direito após o golpe de 1964: Mobral e Ensino Supletivo}

Após o golpe civil-militar de 1964 houve a necessidade do "Novo Regime" legitimar o seu poder. A partir disso, uma das ferramentas encontradas pelos militares para atingir esse objetivo foi a outorga de uma Constituição aparentemente legítima, mas que se tratava de mais uma imposição da ditadura que se estabelecia no país. Nesse contexto, a educação seria um importante instrumento para que o governo militar pudesse implantar sua política de "unidade e segurança nacional".

Assim, em meio a um ambiente de restrições e imposições, foi outorgada a Constituição de 1967, que possuía diversas contradições, como o fato de que, ao mesmo tempo em que o texto apresentava a obrigatoriedade de acesso à escola para a faixa dos sete aos quatorze anos de idade, permitia o trabalho infantil a partir dos doze anos. Nesse caso, é possível refletir sobre o impacto dessa medida no quantitativo de estudantes que tiveram sua escolarização interrompida. Em consequência, visualizamos um retrocesso na política social do governo militar, já que a Carta de 1946 estabelecia quatorze anos como idade mínima para o trabalho de adolescentes.

No tocante ao público jovem e adulto, as respostas vieram com a criação do Movimento Brasileiro de Alfabetização (Mobral), em 1967, e a implantação do Ensino Supletivo, em 1971. Ambas as propostas tiveram grande visibilidade nesse período.

O Mobral foi um programa que tinha como meta alfabetizar adultos das mais variadas localidades do país. Diferente de outros programas, no Mobral houve investimento de recursos suficientes para a montagem de uma organização de âmbito nacional. Os recursos tinham, de 
ABREU JÚNIOR, Jupter Martins de; PRADO, Helen Wanderley do. A educação de jovens e adultos no Brasil: entre trajetórias descontínuas e a expectativa do direito

acordo com Paiva (2009), origem na indicação de até $2 \%$ do imposto de renda devido por pessoas jurídicas. Complementados, no início das atividades, por $24 \%$ da receita líquida da Loteria Esportiva.

Durante os anos de 1970, o Mobral diversificou sua atuação, visando aumentar a longevidade do programa. O que responderia às críticas com relação aos resultados apresentados, principalmente no que se referia à insuficiência no domínio dos elementos básicos da leitura e da escrita que era capaz de promover. Além dessas questões, é ressaltado por Paiva (2009) o fato de existir baixa articulação com o ensino básico, aspecto que dificultava atender demandas relativas à continuidade dos estudos por parte de seus estudantes.

Em linhas gerais, o Mobral representou o reconhecimento de alguns segmentos do Estado sobre a necessidade de saber ler e escrever dos jovens e adultos trabalhadores, além da urgência de se ofertar escolarização a uma parcela da sociedade interditada desse direito. Esse reconhecimento também pôde ser verificado à medida que o Movimento obteve recursos consideráveis para a época, além de autonomia administrativa.

Entretanto, conforme comenta Paiva (2009), esses aspectos não possuíam relação com a perspectiva do direito. Já que a existência do Mobral teve como meta principal aumentar a força produtiva dos trabalhadores, no intuito de "tirar" o Brasil do atraso e, assim, conferir legitimidade ao regime junto às camadas da população beneficiadas pelo programa. Conforme o slogan do período: "este é um país que vai pra frente".

O Mobral foi extinto em setembro de 1985, momento em que já se encontrava estigmatizado como modelo de educação domesticadora e de baixa qualidade, estando desacreditado no meio político e educacional. A estrutura existente foi transferida para a Fundação Nacional para Educação de Jovens e Adultos (Educar), regulamentada nesse mesmo ano. Essa fundação passou a apoiar técnica e financeiramente as iniciativas de alfabetização realizadas pelos governos estaduais, municipais e entidades civis.

No mesmo período de vigência do Mobral foram sancionadas diversas leis e decretos que tinham como meta regulamentar as ações relacionadas à educação. Dentre essas leis, uma das mais significativas para o que hoje se denomina educação básica foi a Lei $n^{\circ}$ 5.692/1971, que regulamentou o Ensino Supletivo e fixou normativas gerais para o ensino de $1^{\circ}$ e $2^{\circ}$ graus, atualmente equivalentes ao ensino fundamental e ensino médio (BRASIL, 1971).

Os direcionamentos estabelecidos para o Ensino Supletivo deveriam se realizar a partir da prioridade à formação e ao aperfeiçoamento para o trabalho. Além de uma liberdade de organização a qual evitasse que a proposta se tornasse somente um ensino regular em tempo 
ABREU JÚNIOR, Jupter Martins de; PRADO, Helen Wanderley do. A educação de jovens e adultos no Brasil: entre trajetórias descontínuas e a expectativa do direito

reduzido. Entretanto, a proposta, em termos práticos, teve a suplência como o aspecto que mais se tornou visível.

Destaca-se que a maior visibilidade alcançada pela suplência pode ser compreendida como um processo de "internalização" do Ensino Supletivo. A "internalização", conforme destaca Mészaros (2008), é um movimento no qual o indivíduo incorpora como suas as metas de reprodução do sistema econômico vigente. Nesse caso, significa a busca por resultados e processos aligeirados, na intenção de legitimar a sua condição na hierarquia social, moldando suas expectativas e conduta ao estipulado pela ordem estabelecida. Deste modo, esse processo insere-se como um instrumento que tenta conformar aos interesses do sistema econômico as práticas sociais e direitos adquiridos, como é o caso da educação.

Esse movimento pode ser identificado quando jovens e adultos com trajetórias descontínuas cogitam um possível retorno aos bancos escolares, e a sua busca tem como foco o diploma como materialização de um possível emprego, continuidade dos estudos, entre outras motivações, sempre na busca de algo que seja semelhante ao Ensino Supletivo. Nesse ínterim, deve ser destacado que, mais de vinte anos após o fim da proposta, o imaginário de alguns setores da sociedade ainda aponta para esse formato como uma possibilidade de acesso à educação, resumindo-se na recorrente pergunta: “Esse curso é supletivo?”. Este pensamento também pode ser materializado nas placas e cartazes estampados nas fachadas de algumas escolas que ofertam a modalidade EJA.

Em contraposição a esses fatos, Mészaros (2008) ressalta que processos de “internalização", como é o caso do Ensino Supletivo, precisam ser confrontados com todas as suas dimensões, visíveis e ocultas. O autor propõe, ainda, que deveriam existir movimentos que pudessem substituir as formas onipresentes e profundamente enraizadas de "internalização" mistificadora por uma alternativa concreta abrangente. De forma que esta pudesse tornar mais efetivas as demandas do direito à educação, tornando-o direito à aprendizagem.

A proposta do Ensino Supletivo teve vigência até a regulamentação da LDBEN n ${ }^{\circ}$ 9.394/1996, período em que se estabeleceu a EJA como modalidade da educação básica. No texto da LDBEN reafirmou-se o direito de jovens e adultos trabalhadores à escolarização, sendo consideradas as especificidades da educação de jovens e adultos, além do dever do poder público em ofertá-la gratuitamente.

De forma geral, dentre as propostas existentes para o público jovem e adulto no período da ditadura civil-militar, o Mobral e o Ensino Supletivo foram as que tiveram maior visibilidade. Situando-se, portanto, num campo de atuação que integrava os planos de desenvolvimento 
ABREU JÚNIOR, Jupter Martins de; PRADO, Helen Wanderley do. A educação de jovens e adultos no Brasil: entre trajetórias descontínuas e a expectativa do direito

econômico e social. Ressalta-se, ainda, que estas propostas foram, por vezes, tratadas como políticas indutivas, complementadas e esclarecidas por meio de documentos orientadores. Afastando-as da perspectiva do direito à educação por parecerem descompromissadas com uma aprendizagem efetiva.

\section{A EJA na redemocratização}

Após oito anos da promulgação da Constituição Federal de 1988, a Lei no 9.394/1996, a nova LDBEN, regulamentou a educação no país, trazendo algumas proposições para o campo da educação de jovens e adultos (BRASIL, 1996). Dentre essas alterações, destacamos o estabelecimento da idade mínima para que os sujeitos pudessem se submeter a exames de certificação, denominados exames supletivos. Destaca-se que, apesar da similaridade na nomenclatura, esta proposta não possui relação com o Ensino Supletivo regulamentado pela Lei $n^{\circ}$ 5.692/1971. A idade estabelecida para a submissão a esses exames foi fixada em quinze anos para o ensino fundamental e dezoito anos para o ensino médio.

Entretanto, verifica-se a existência de sistemas de ensino e/ou gestões locais que interpretam esse trecho da LDBEN de maneira equivocada ou até mesmo perversa, entendendo essa faixa etária para além da realização dos exames de certificação. Alguns sistemas/gestões consideram que a idade mínima expressa na legislação representaria uma obrigatoriedade de matrícula/transferência para a modalidade EJA, impedindo, assim, a opção de continuidade dos estudantes no ensino fundamental ou ensino médio "regular", somente porque já possuem quinze ou dezoito anos. Os impactos e motivos dessas ações no cotidiano escolar carecem de pesquisas mais aprofundadas.

No contexto político e social, o mandato do presidente Fernando Henrique Cardoso, entre 1995 e 2002, representou um tempo em que, de acordo com Machado (2009, p. 20), o Estado brasileiro caminhava na "contramão da garantia do direito explicitado nos incisos do Art. $4^{\circ}$ da LDBEN”. Essa afirmação se baseia no fato de que na última década do século XX o percentual de analfabetos na população brasileira acima de quinze anos de idade era de $15,5 \%$, o que representava cerca de vinte milhões de pessoas.

Nesse período, apesar da instabilidade na oferta da EJA como política pública, houve a ampliação dos canais de participação da sociedade civil, que teve como uma de suas ferramentas a criação de conselhos de direitos. Na área da educação, essas formas de participação têm como elemento fundamental o Conselho Nacional de Educação (CNE), proposto a partir da LDBEN, $n^{\circ}$ 9.394/1996, que potencializou a idealização de conselhos estaduais e municipais. Inseridos nesse 
ABREU JÚNIOR, Jupter Martins de; PRADO, Helen Wanderley do. A educação de jovens e adultos no Brasil: entre trajetórias descontínuas e a expectativa do direito

contexto, foram criados os fóruns de EJA, que constituíram espaços de mobilização dos diferentes segmentos que atuam na modalidade. Esses fóruns eram organizados nos estados, no Distrito Federal, além de fóruns regionais, sempre operando em defesa da EJA como política pública (MACHADO, 2009).

Esses instrumentos de participação da sociedade civil se tornaram ferramentas para uma mobilização em torno das discussões sobre a EJA, criando demandas para os conselhos de educação tanto em nível estadual quanto nacional. Esse movimento desencadeou a realização de audiências públicas e reuniões pelo CNE para discutir a temática, cujo resultado se encontra sistematizado no Parecer $n^{\circ} 11 / 2000$, que se tornou um documento referência para embasar os debates sobre a modalidade (BRASIL, 2000).

Nas primeiras décadas do século XXI, as questões relacionadas às demandas da EJA permaneceram como preocupações para os que pesquisam a modalidade enquanto política pública. Isso porque os dados disponibilizados pelo Instituto Brasileiro de Geografia e Estatística (IBGE) por meio da Pesquisa Nacional por Amostra de Domicílios (PNAD), realizada em 2018, informam que ainda existem $6,8 \%$ de analfabetos na população brasileira acima de quinze anos, o que significa cerca de 11,3 milhões de pessoas (BRASIL, 2018). Essa informação reforça a necessidade de mobilizar jovens e adultos de todo território nacional, visando um retorno com êxito ao processo de escolarização. Pois, conforme estabelecido na LDBEN no 9.394/1996 e na Constituição Federal de 1988, como consta na interpretação de Cury (2008a, p. 296), a educação escolar é:

[...] erigida em bem público, de caráter próprio, por ser ela em si cidadã. E por implicar a cidadania no seu exercício consciente, por qualificar para o mundo do trabalho, por ser gratuita e obrigatória no ensino fundamental, por ser gratuita e progressivamente obrigatória no ensino médio [...] a educação básica é dever do Estado.

Assim, é importante ressaltar que a percepção de que a educação deve ser reconhecida como direito impulsionou o Estado na ação de assegurá-la ao público da EJA. O direito à educação, enquanto direito público subjetivo, obriga a interferência do Estado para a diminuição de desigualdades sociais e de hierarquias existentes na sociedade, para que o direito se concretize de fato.

Contudo, no caso da EJA, observa-se uma trajetória com histórico voltado para propostas de "erradicação do analfabetismo", apresentadas sob a forma de campanhas e programas, ou de ofertas "compensatórias". Ainda que fossem reconhecidas como direito constitucional, essas iniciativas eram descontínuas. Além de terem caráter aligeirado e, por vezes, seguirem uma lógica que permanecia assegurando privilégios para os setores mais abastados, que eram historicamente favorecidos. 
ABREU JÚNIOR, Jupter Martins de; PRADO, Helen Wanderley do. A educação de jovens e adultos no Brasil: entre trajetórias descontínuas e a expectativa do direito

\section{Considerações finais}

Após mais de vinte anos da regulamentação da LDBEN, n 9.394/1996, pode-se afirmar que as políticas de acesso, permanência e êxito, que visam potencializar as condições de oferta e elevação de escolaridade, ainda são frágeis e insuficientes para o atendimento ao público da EJA. Verificou-se que, entre embates e proposições, houve um gradativo reconhecimento de que é função do Estado incluir esses setores da sociedade, além de que, com esses encaminhamentos o termo "acesso à educação para todos" se tornou frequentemente utilizado pelas políticas educacionais, induzindo à percepção de que esses grupos teriam seus direitos garantidos, revertendo essa situação. Entretanto, a modalidade permanece marcada pela descontinuidade das políticas públicas, precárias no sentido de assegurar o cumprimento do direito à educação nos termos estabelecidos pela lei.

Como consequência da trajetória apresentada neste artigo, destacamos que algumas iniciativas foram enfraquecidas devido à realidade dos processos construídos na sociedade brasileira. Dentre esses fatos, foram exemplificados o impedimento de maiores de vinte e cinco anos de se matricularem em cursos de formação de professores, a contradição da Constituição de 1967, permitindo o trabalho infantil a partir de doze anos quando a idade escolar era até catorze anos, ou mesmo a interpretação equivocada da idade mínima para os exames de certificação por parte de alguns sistemas de ensino e/ou gestões locais. Todos esses tópicos revelaram fragilidades que podem e devem ser aprofundadas para mostrar e contextualizar as circunstâncias em que o Estado brasileiro não garantiu escolarização para setores específicos da sociedade.

Para esses grupos implicados, excluídos dos direitos humanos mais básicos, somente restaram condições mínimas de sobrevivência, o que mais uma vez nos faz refletir sobre os avanços obtidos nas últimas décadas, no intento de planejar estratégias para superar esses impedimentos. Esses direcionamentos destacados neste trabalho ressaltam a premissa de que a existência de estatutos legais não garante o cumprimento de direitos. Mas, à medida que essas normativas impõem ações ao Estado e à sociedade, o direito pode se instituir na prática, caso esses entes cumpram seus deveres constitucionais.

Por outro lado, também é relevante ressaltar que a educação de jovens e adultos passou por avanços nas últimas décadas, dentre os quais destacamos a sua incorporação como modalidade de ensino da educação básica, em contraposição à ideia de subsistema existente à época do Ensino Supletivo; a regulamentação dos conselhos estaduais, em nível municipal, estadual e nacional; além da constituição dos fóruns de EJA, que materializaram a participação da sociedade civil em um 
ABREU JÚNIOR, Jupter Martins de; PRADO, Helen Wanderley do. A educação de jovens e adultos no Brasil: entre trajetórias descontínuas e a expectativa do direito

debate a partir das demandas da modalidade. Todas essas ações e normativas contribuíram de maneira efetiva no sentido de ampliar a discussão sobre a modalidade sob diferentes perspectivas.

Nesse sentido, reconhecer a educação como direito implica em ratificar os princípios da igualdade e da diversidade enquanto elementos vitais de transformação das instituições educacionais. E esses movimentos, no caso da EJA, devem permitir não só o acesso ou mesmo a permanência, mas também o direito à aprendizagem, visando superar a lógica da educação compensatória ao incluir, de fato, esse coletivo de jovens e adultos que tiveram direitos negados e trajetórias interrompidas.

\section{Referências}

BOBBIO, Norberto. A Era dos direitos. Rio de Janeiro: Editora Campos, 2004.

BRASIL. Congresso Nacional. Constituição da República Federativa do Brasil de 1988. 05 de outubro de 1988. Disponível em: < http://www.planalto.gov.br/ccivil_03/ constituicao/constituicao.htm>. Acesso em: 12 mar. 2020.

BRASIL. Lei $n^{\circ}$ 5.692, de 11 de agosto de 1971. Fixa Diretrizes e Bases para o ensino de $1^{\circ}$ e $2^{\circ}$ graus, e dá outras providências. 1971. Disponível em: <http://www.planalto. gov.br/ccivil_03/leis/15692.htm>. Acesso em: 16 fev. 2020.

BRASIL. Lei no 9.394, de 20 de dezembro de 1996. Estabelece as diretrizes e bases da educação nacional. 1996. Disponível em <http://www.planalto.gov.br/ccivil_03/leis/19 394.htm> Acesso em: 10 fev. 2020.

BRASIL. Parecer CNE/CEB n 11/2000. 10 de maio de 2000. Disponível em: <http://portal.mec.gov.br/cne/arquivos/pdf/PCB11_2000.pdf>. Acesso em: 09 dez 2019.

CURY, Carlos Roberto Jamil. A educação básica como direito. Cadernos de Pesquisa. São Paulo, v. 38, n. 134, p. 293-303, 2008a. Disponível em: < https://www.scielo.br/ scielo.php?script=sci_arttext\&pid=S0100-15742008000200002 >. Acesso em: 19 mar. 2020.

CURY, Carlos Roberto Jamil. A educação escolar, a exclusão e seus destinatários. Educação em Revista. Belo Horizonte, n. 48, p. 205-222, 2008b. Disponível em: < https://www.scielo.br/scielo. php?script $=$ sci_arttext\&pid=S0102-46982008000200010\&lng $=$ pt\&tlng=pt $>$. Acesso em: 15 mar. 2020.

CURY, Carlos Roberto Jamil. Fundamentos de uma educação para os direitos humanos. Revista do COGEIME, v. 41, p. 131-144, 2013.

FERRARO, Alceu Ravanello; KREIDLOW, Daniel. Analfabetismo no Brasil: configuração e gênese das desigualdades regionais. Educação e Realidade. v. 29, n. 2, p. 179-200, jul-dez 2004. Disponível em: < https://seer.ufrgs.br/educacaoerealidade/arti cle/view/25401>. Acesso em: 11 mar. 2020. 
MACHADO, Maria Margarida. A educação de jovens e adultos no Brasil pós-Lei no 9.394/96: a possibilidade de constituir-se como política pública. Em Aberto. Brasília, v. 22, n. 82, p. 17-39, novembro/2009.

MARSHALL, Thomas. Cidadania e Classe Social. 2. ed. Brasília: Senado Federal, Centro de Estudos Estratégicos, Ministério da Ciência e Tecnologia, 2002.

MÉSZÁROS, István. A educação para além do capital. Tradução de Isa Tavares. São Paulo: Boitempo, 2008.

PAIVA, Jane. Os sentidos do direito à educação para jovens e adultos. 1. ed. Rio de Janeiro: Faperj, 2009. v. 1, p. 232.

PNAD Contínua 2018: educação avança no país, mas desigualdades raciais e por região persistem. Agência IBGE Notícias, 19 jun. 2019. Disponível em: <https://agenciadenoti cias.ibge.gov.br/agencia-sala-de-imprensa/2013-agencia-de-noticias/releases/24857-pna dcontinua-2018-educacao-avanca-no-pais-mas-desigualdades-raciais-e-por-regiao-persi stem $>$. Acesso em: 20 fev. 2020.

ROMANELLI, Otaíza de Oliveira. História da Educação no Brasil (1930/1973). 40 ed. Petrópolis, RJ: Vozes, 2014.

SHIROMA, Eneida Oto; MORAES, Maria Célia Marcondes de; EVANGELISTA, Olinda. Política educacional. 4. ed. Rio de Janeiro: Lamparina, 2004. p. 128.

Recebido em: 24 mar. 2020/ Aprovado em: 06 jul. 2020.

Recebido em: 30 mar. 2020/ Aprovado em: 06 jul. 2020

\section{$\underline{\text { Cite como }}$}

(ABNT NBR 6023:2018)

ABREU JÚNIOR, Jupter Martins de; PRADO, Helen Wanderley do. A educação de jovens e adultos no Brasil: entre trajetórias descontínuas e a expectativa do direito. Dialogia, São Paulo, n. 35, p. 93-106, maio/ago. 2020. Disponível em:

https://doi.org/10.5585/dialogia.n35.16910.

\section{American Psychological Association (APA)}

Abreu Júnior, J. M., Prado, H. W. (2020, maio/ago.). A educação de jovens e adultos no Brasil: entre trajetórias descontínuas e a expectativa do direito. Dialogia, São Paulo, 35, p. 93-106. https://doi.org/10.5585/dialogia.n35.16910. 